\title{
Formation of Sn/Ag/C Nanoalloy Through Laser Ablation of Ag Target and Simultaneous Decomposition of TMT in the Gas Phase
}

\author{
N. Murafa***, T. Křenek***, J. Pola*, J. Šubrt***, P. Bezdička*** \\ *Laboratory of Laser Chemistry, Institute of Chemical Process Fundamentals, ASCR, v.v.i., 16502 \\ Prague, Czech Republic
}

**University of West Bohemia, 30614 Plzen, Czech Republic

***Institute of Inorganic Chemistry of the ASCR, v. v. i., 25068 Řež, Czech Republic

Increasing environmental and health concerns over the toxicity of lead-based solders have provided an inevitable driving force for the development of lead free solders. Among these new lead-free solders belongs Sn-Ag alloy which is promising alternative due to its higher strength and superior resistance to creep and thermal fatigue from the formation of fine $\mathrm{Ag} 3 \mathrm{Sn}$ in intermetallic compound. To Sn-Ag solders have been devoted a many papers $[1,2,3]$.

This work brings a novel approach for nanoalloy synthesis consisting in highly focused radiation at the surface of metal target which leads to the ablation/etching of metal atoms and induces interaction with eventually present gas phase precursor resulting in dielectric breakdown.

Proposal approach consists of two simultaneously proceeding processes: (I) laser ablation/etching of metal target, (II) decomposition of reactant in the gas phase through dielectric breakdown.

These laser processes are able to yield simultaneously clusters of two metals (some obtained by laser ablation/etching of metal target, the others from gas phase decomposition of reactant) which interact in the gas phase and allow deposition of mixed nanosized structure. This process provides heating and cooling within very short time intervals that are of the order of $\mu \mathrm{s}[4,5]$.

We have examined a novel approach to gas-phase deposition of nanosized Sn-Ag alloys embedded in a carbonaceous phase based on IR laser ablation of $\mathrm{Ag}$ in a plume (dielectric breakdown) of tetramethyltin (TMT). In this approach, Ag nanoparticles are propelled from the target and mixed with Sn clusters produced in the gas phase by the decomposition of TMT. The resulting $\mathrm{Sn} / \mathrm{Ag}$ structures are during their formation subject to heating and subsequent cooling within some $\mu$ s. The decomposing TMT, serving as a carbon source, may provide additional stabilization of these metastable structures.

We obtained thin $\mathrm{Sn} / \mathrm{Ag} / \mathrm{C}$ films that were characterized by scanning electron microscopy (SEM) Philips XL30 CP Fig. 1.(a,b) equipped with EDX (energy dispersive X-ray), Robinson, SE (secondary electron) and BSE (back-scattered electron) detectors and Raman spectroscopy Fig. 3.(b). Micro X-ray diffraction ( $\mu$-XRD) patterns were obtained by Siemens D5005 instrument Fig. 3.(a) using $\mathrm{CuK} \alpha$ radiation $(40 \mathrm{kV}, 30 \mathrm{~mA})$ and diffracted beam monochromator.

Qualitative analysis was performed with the Eva Application and the Xpert HighScore using the JCPDS PDF-2 database. High-resolution transmission electron microscopy (HRTEM) JEOL JEM 3010 Fig. 2. and Selected Area Electron Diffraction (SAED) and we draw some conclusions on the structure of these materials. We revealed that obtained materials are consist blend of amorphous and crystalline phase correspond to amorphous Sn-Ag-C alloy and crystalline nanobodies of $\beta$-Sn covered by crystalline shell. 


\section{References:}

[1] I. Shohji, T. Yoshida, T. Takahashi, S. Hioki: Mat. Sci. En., A366 (2004), 50-55

[2] K.S.Kim, S.H.Huh, K.Suganuma: Mater. Sci. Eng., A333, 106 (2002)

[3] K.S.Kim, S.H.Huh, K.Suganuma: J. Alloy. Compd. 352,226 (2003)

[4] A.M. Ronn, Chem. Phys. Lett. 1976, 42, 202-204

[5] D.K. Russell, Chem. Soc. Rev. 1990, 19, 407-437

[6] This work was supported by Ministry of Education, Youth and Sports of the CR (LC523)
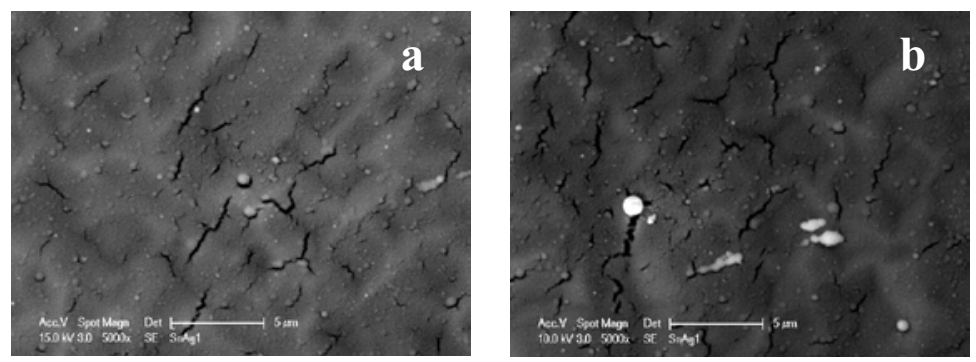

Fig. 1. (a,b) SEM images of the $\mathrm{Sn} / \mathrm{Ag} / \mathrm{C}$ deposit
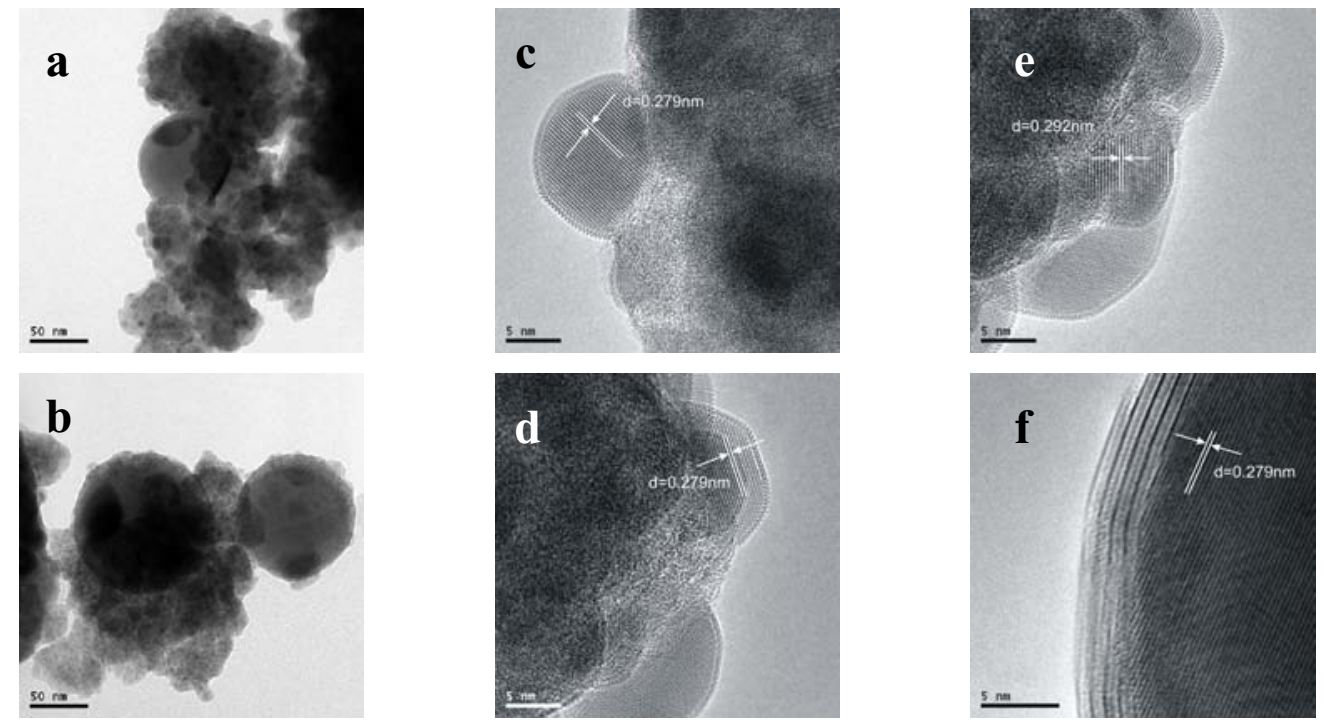

Fig. 2. TEM (a,b) and HRTEM (c-f) micrographs of the $\mathrm{Sn} / \mathrm{Ag} / \mathrm{C}$ deposit
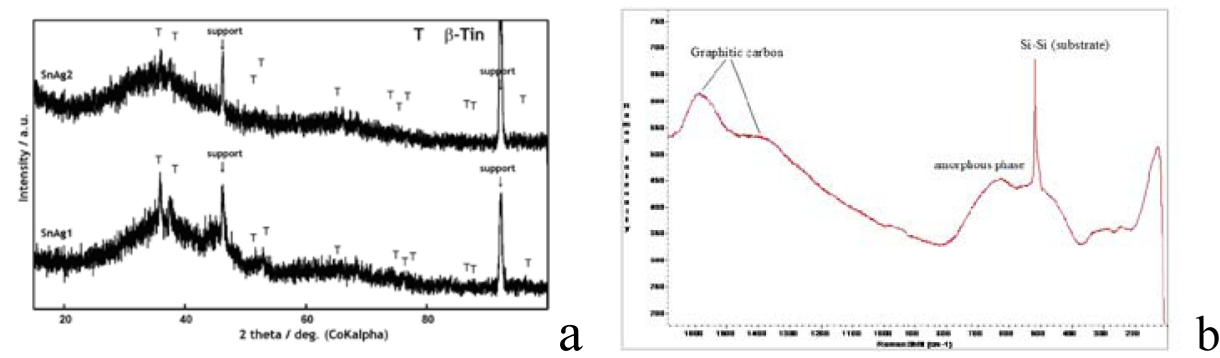

Fig. 3. (a) $\mu$-XRD analysis of the $\mathrm{Sn} / \mathrm{Ag} / \mathrm{C}$ deposit before (SnAg1) and after (SnAg2) heating to $180{ }^{\circ} \mathrm{C}$, (b) Typical Raman spectrum of the $\mathrm{Sn} / \mathrm{Ag} / \mathrm{C}$ deposit 